\title{
Higher Vocational College Students' Public Spirit Cultivation Countermeasure Research in "Internet +" Era
}

\author{
Wu Hongying \\ Shunde Polytechnic \\ 1.2015 annual Foshan Social Science Planning Project: Research on the quality and network
}

literacy of Foshan citizens under the background of "Internet +", 2015-BZ49;

2.Shunde Polytechnic "innovation and strong school project" independent innovation ability to improve the type of project: the beauty of the city - citizens quality cooperative cultivation center stage results, 2015-KJZX048.

\begin{abstract}
Keywords: Internet +; Public spirit; Higher vocational college students; Cultivating countermeasures
\end{abstract}

\begin{abstract}
The main feature of modern society is publicity, and public spirit is the response to modern characteristics. Our country citizen's public spirit quality has greatly ascended. Citizen's public spirits such as main body consciousness, rights and obligations consciousness, public responsibility consciousness and maintain publicity symbol human modernization degree. More important human resources are college students in China, who are they mainstay for the construction of China's future, and the future belongs to their society. Their public spirit plays an important exemplary and leading role to the other members of the society. In the era of Internet + environment, a lot of college students in higher vocational colleges have the phenomenon of lack of public spirit. In such a situation, as well as the importance of college students' public spirit, the research of it is very meaningful.

Internet is filled with high efficient, abundant network information, but in the Internet, we must establish use and thought "firewall". Construction of higher vocational college students' public spirit should strengthen and innovate constantly, on the basis of the guarantee to keep pace with the Times. In the cultivation of public spirit in higher vocational college students, embody the Times and regularity, and give creative and constructive in the construction of public spirit. Public spirit cultivation related issues of current higher vocational college students under the era of "Internet +" are analyzed, and on the results of the analysis, the corresponding solution strategy is put forward.
\end{abstract}

\section{I. "INTERNET +" IMPACT ON HIGHER VOCATIONAL COLLEGE STUDENTS' PUBLIC SPIRIT}

The updated speed and rich variety of network culture in the "Internet + " have a certain influence on students. Positive impacts involve widening students' view, pleasing the spirit of the students, increasing students' knowledge and cultivating students' temperament and other positive impacts. Every coin has its two sides. The development of the network brings positive influence, at the same time also brings some negative effect. [1]

\section{A. Positive influence}

First of all, the Internet is helpful to cultivate students' spirit of cooperation, and the network has certain interactivity. A lot of network behavior is done by collaboration between people, and college students are the main participants, who are full of enthusiasm for new things and knowledge which has been especially acute in the network. In virtual environment, it is more likely to give college students spiritual solace, and college students are more prone to collaborate with each other in the network, and the network's good content is very easy to attract students' attention, thus produces a collection of functions such as lead utility, great national spirit, age spirit and scientific humanistic spirit. Healthy network spirit is bound to promote college students' cooperation spirit. The network culture has strong team cohesion, and can help the collectivist values very well. The network also has a profound impact on college students' sense of faith, and has effect on awakening service consciousness of college students. Interest is beneficial to urge college students engage in social 
services, actively help social vulnerable groups and train the students care for social and environment. Healthy network culture not only can be a good guide in giving the students faith of serving the masses, and is conducive to college students' constant pursuit of self-perfection and their comprehensive development realization.

\section{$B$. The negative impacts}

There are a lot of positive right content in Internet environment, at the same time there are a lot of unhealthy content, such as crime, poor culture, etc. This bad information has a very negative effect on college students. The negative content in the network containing complex garbage, negative information has adverse impact on the idea of unity, love dedication, social care and mutual assistance in public consciousness of college students, and has impact on the values of contemporary college students. (2) Secondly, bad ideas on the network have adverse impact on public value orientation of college students. Contemporary network is filled with hedonism and egoism. Under the impact of network effect, college students cling to capitalism culture which benign social value orientation. The impact of various criminal behaviors in the network makes people face crisis of cybercrime while enjoying network's convenience. Illegal behavior such as fishing websites weakens college students' right ideological and moral consciousness, causing split personality of college students, which harms the cultivation of university community spirit. In addition the disorder in network environment can make university community ideology chaos. The freedom in the network decreases the consciousness of the social responsibility of college students. And easy to produce intense conflict with correct ideological culture in the cultivation of college students' public awareness, which unravels the social constant value effect on the strength of college students, making the status of split idea in university students. These are not for the interests of college students' public spirit cultivation. [3]

Network is a kind of new entertainment culture, which has great impact on the social construction. A lot of students after contact network, indulge in the network due to all kinds of new things in the network, which has caused severe damage to the body, at the same time the network is full of pornography and violence which harms students' thought and psychology, and is very easy to cause the students' mental breakdown and leads to violence. These behaviors make a tremendous negative impact on public environment and atmosphere. We can learn in the narration above that the network has certain negative effects on college students' public spirit cultivation. How to correctly display the positive effects of the Internet on college students' public spirit cultivation, eliminate the negative impact of network on college students, and construct the positive contribution for college students' public spirit cultivation will be the focus of this article.

\section{HIGHER VOCATIONAL COLLEGE STUDENTS' PUBLIC SPIRIT CULTIVATING STRATEGIES IN THE ERA OF "INTERNET +"}

Along with the network popularization in higher vocational college students' life, college students' learning and life have been inseparable from the public network gradually, and the network has also been gradually become the key of college students' ideological and moral qualities and scientific and cultural learning content and way. College students are the master of society in the future, so the cultivation of public spirit is the important content of contemporary higher vocational college students' spirit. How to implement public spirit cultivation in an extremely complex network environment is very important. From school, society, network, and higher vocational college students and other aspects, the corresponding cultivation strategies on public spirit of college students are discussed.

\section{A. Optimize college public welfare resources}

College students are important members of public welfare team, which has extremely important influence on the technology spirit of the future society, and is an important content of university thought political education to popularize public college students thought. Our country's higher vocational colleges instill public philosophy and public awareness for students, and combine the characteristics of students to make the corresponding development of public welfare spirit education, and enrich the content of school activities. Cultivate college students' public spirit through the 
above three aspects.

First of all, we must strengthen student's public welfare concept. The key idea of public education is the action to save the poor, dedicated collective and solidarity. Colleges and universities carry on the public and education of the concept of public awareness on the full understanding of the concept, and make students realize the importance of public education. Second expand the education of public events and enlightenment in colleges and universities to promote college students' spirit of dedication, unity and mutual assistance for collective welfare cultivation, and promote the university students’ public spirit cultivation. [4]

On the content of public education, first include the content of public education in higher vocational college students' ideological and moral construction, public education is an important ideological and moral part. In ideological and political education, strengthen the understanding of public spirit. Secondly clear the connotation of public spirit, which is established on the system of socialist core values. The public spirit of college students in our country should have socialist characteristics, and combine the spirit of patriotism, etc. of our country. In this way can we achieve the purpose of public welfare spirit to serve the broad masses in our country?

Develop diverse public education activities on campus, and set up a variety of community public to enrich the content of higher vocational college students' public welfare activities. In higher vocational colleges, actively carry out a variety of community volunteer activities, such as let the students do cleaning and maintenance of campus facilities, students volunteer fixing bicycle, computer, etc.; At the same time, call on the students get out of the campus for social service, etc., improve public enthusiasm of students, and cultivate public spirit of college students. In higher vocational colleges, set up community public interest at the same time, organize, plan on a regular basis to carry out public welfare activities, not only enrich the spare life of students, at the same time also realize the cultivation of student's public spirit and comprehensive quality ascension.

\section{$B$. The construction of public culture}

Network is the basis of network cultural transmission and innovation things, and a way of our government network culture construction. The government bears the important responsibility of network cultural content purification. The government should maximize investment on public welfare in building a network, make full use of network advantages of rapidness, efficiency, and large package content, and develop the positive effect of the network technology and undertake government public service network construction.

Firstly, the government should build a good platform of public welfare culture and environment; establish a public service nature pulpit, BBS, etc. At the same time, expand public service and public welfare activities and emotional public consultation on the network, [5] realize government public websites' affinity, and enhance the cohesion of the people. Enhance the influence of the government public websites. In addition, closely cooperate with the departments of the government, take practical means for spiritual culture construction, remove the bad information on the net, and realize the effective cleaning of network bad information. On the network education, students should consciously resist the bad information, maintain fairness and justice, reward true information, criticize ugly false, cheat [6], establish corresponding legal punishment measures, and establish the incentive to maintain public spirit. To be positive in cooperation with the government and the school, make strict supervision on students and the relevant network, sanction against illegal molecules on the network, and build a healthy, civilized, harmonious and orderly public cultural environment for contemporary college students.

C. The improvement of students' self-public welfare education ability

College students, in self-public welfare education, should take the initiative to take measures to realize students' ideological transformation into public welfare. Due to the growth characteristics of higher vocational college students, their self-discipline ability is low, and they are easy to indulge network behavior, at the same time, a lot of students act in accordance with their own work principle on the network, so in the Internet age, it is very important to improve the students' ability of self-public welfare education.

College students' public spirit in network era is an integral part of systematic engineering. Besides 
the needs of government and school cooperation, it requires students to attach importance to public spirit, follow national and social public welfare propaganda, and actively learn all kinds of good deeds, learn from role models about important public spirit, and make their own contribution for the development of public spirit. The specific requirements of self-public education of vocational college students should be determined by college students' intake of public knowledge and the time of public behavior. College students should actively participate in public welfare activities organized by the school, and the activities of the real practice to cultivate public spirit in public welfare activities such as sending warmth to children in the mountain areas and help the elderly to improve their ability of public welfare activities. [7]

\section{SUMMARY}

On the analysis of the present situation of higher vocational college students' public spirit under Internet + environment, public spirit of modern college students has both positive impact and negative impact, so we have to do a good job in all aspects of the work in a specific environment according to the different influence of network on public spirit earnestly. Achieve the aim of training students' public spirit in actively carried out various strategies.

\section{REFERENCE}

[1] Li Leilei. The cultivation of network culture and national spirit of contemporary university students [D]. Henan University of Science and Technology, 2012.

[2] Han Zhijun. Contemporary college students' public spirit fosters research [D]. Capital Normal University, 2013.

[3] Li Qing. The higher vocational college students' public spirit countermeasure research under network environment [D]. Hunan University, 2013.

[4] Shi Xiaojuan. College students' network behavior ethics research [D]. Northwest Agriculture and Forestry University of Science and Technology, 2014.

[5] Yu Kai. The handset media's influence on higher vocational college students and countermeasures research [D]. Northwest Agriculture and Forestry University of Science and Technology, 2014.

[6] Wang Yanan. Community democratic construction research of college students' network [D]. Yanshan University, 2012.

[7] Guo Lijun. Public spirit cultivating college students research in modern horizon. [D]. East China Normal University, 2011. 